\title{
Analisis Pemanfaatan Aplikasi E-Commerce Aspek Kewirausahaan Dalam Peningkatan Kualitas Layanan Costumer Femax Di CV. Karya Solenoida
}

\author{
Eko Hariadi, Afnan Rosyidi, Widada \\ Amikom Surakarta \\ eko.h@dosen.amikomsolo.ac.id
}

\begin{abstract}
ABSTRAK
Pemanfaatan aplikasi e-commerce dilihat dari aspek kewirausahaan dengan variabel manfaat aplikasi ecommerce dari perusahaan, kemudahan akses internet untuk melihat website, sikap konsumen untuk menentukan layanan yang tepat, niat pelanggan untuk menggunakan internet dapat menentukan kepuasan kualitas layanan konsumen. Penelitian ini dilakukan pada konsumen yang memanfaatkan produk Femax di CV. Karya Solenoida. Responden berjumlah 100 orang diolah menggunakan Structural Equation Model (SEM) sofware Amos versi 22. Hasil perhitungan tertinggi menunjukkan pengaruh terhadap variabel kemudahan akses internet dengan manfaat $e$-commerce yang disediakan perusahaan sebesar 1,630. Pemanfaatan aplikasi e-commerce sebagai strategi bisnis kewirausahaan oleh Perusahaan mempengaruhi Manfaat bagi Konsumen tentang penggunaan Website sebesar 1,236. Pengaruh Website terhadap Kemudahan akses internet sebesar 1,087. Pengaruh sikap dengan niat sebesar 0,898 sedangkan niat mempengaruhi kepuasan sebesar 0,615. Hal ini menunjukkan bahwa Kepuasan Pelanggan ditentukan oleh sikap konsumen untuk memesan layanan dari Perusahaan dengan niat mau menggunakan aplikasi yang ada. Manfaat berpengaruh terhadap kepuasan sebesar 0,423 dan manfaat berpengaruh terhadap sikap sebesar 0,419. Namun demikian variabel yang terkecil adalah variabel Kemudahan berpengaruh terhadap variabel Sikap sebesar 0,088 dan yang tidak berpengaruh hanya variabel Manfaat terhadap variabel Niat sebesar 0,175 . Jadi semakin besar Manfaat Aplikasi E-commerce Perusahaan dan Kemudahan akses internet melalui Website maka semakin besar pula kepuasan konsumen mendapatkan layanan secara maksimal.
\end{abstract}

Keywords : Manfaat, Aplikasi, E-Commerce, Website, Kewirausahaan.

\begin{abstract}
The use of e-commerce applications is seen from the entrepreneurial aspect with the variable benefits of e-commerce applications from the company, easy internet access to view websites, consumer attitudes to determine the right service, customer intention to use the internet can determine customer service quality satisfaction. This research was conducted on consumers who use Femax products at CV. Solenoid work. 100 respondents were processed using the Structural Equation Model (SEM) of Amos version 22 software. The highest calculation result shows the influence on the variable ease of internet access with the benefits of e-commerce provided by the company of 1.630 . The use of e-commerce applications as an entrepreneurial business strategy by the Company affects the benefits for consumers regarding the use of the Website of 1,236. The effect of the website on the ease of internet access is 1.087. The effect of attitude with intention is 0.898 while intention affects satisfaction by 0.615 . This shows that Customer Satisfaction is determined by the attitude of consumers to order services from the Company with the intention of using existing applications. Benefits have an effect on satisfaction by 0.423 and benefits have an effect on attitude by 0.419 . However, the smallest variable is the Ease variable which affects the Attitude variable of 0.088 and the only one that does not affect the intention variable is -0.175 . So the greater the benefits of corporate e-commerce applications and the ease of internet access through the website, the greater the satisfaction of consumers in getting the maximum service.
\end{abstract}

Keywords: Benefits, Applications, E-Commerce, Website, Entrepreneurship. 


\section{PENDAHULUAN}

Kaitannya dengan penelitian ini adalah menganalisis pemanfaatan aplikasi website / e-commerce yang aktif dilihat dari segi aspek kewirausahaan yang telah dijalani untuk meningkatkan kualitas kepuasan layanan konsumen atau pelanggan Femax di CV. Karya Solenoida dengan salah satu model penerimaan pemakaian terhadap teknologi informasi adalah menggunakan model Technology Acceptance Model (TAM) yang dikemukakan oleh Davis (2000) dan dikembangkan pada penelitian lebih lanjut oleh Thong (2002). Penelitian-penelitian yang ada menunjukkan bahwa kebenaran TAM atas berbagai macam sistem penggunaan teknologi informasi pada berbagai jenis instansi dan perusahaan telah diakui oleh para peneliti di dunia (Vaidyanathan, 2005). Perkembangan

Sistem Informasi melalui internet dapat memberikan kontribusi penjelasan tentang barang atau jasa yang ditawarkan. Website usaha perlu dikembangkan untuk meyakinkan pelanggan agar mau berinteraksi dan memesan jasa yang ada. Alamat website www.mekanikprofesional.com adalah salah satu website yang menawarkan jasa layanan khususnya tentang Gurah Mesin untuk Mobil dan Motor yang telah berkembang sejak tahun 2015 sampai sekarang masih eksis. Untuk memberikan pelayanan informasi tentang usaha Gurah Mesin ada website tersebut yang dikembangkan mulai Agustus 2019. Kerangka pemikiran yang diusulkan oleh peneliti dalam mencari keterkaitan pengaruh dan hubungan pemanfaatan e-commerce sebagai strategi bisnis Femax sebagai seorang wirausahawan terhadap kepuasan layanan pelanggan, dipengaruhi oleh faktor sumber daya perusahaan, desain/fitur website yang mempengaruhi kemanfaatan e-commerce, sikap pengguna dan niat pengguna memesan lewat informasi dari website tersebut terhadap kualitas Femax untuk mendapat layanan maksimal dari Perusahaan. Analisa dengan model TAM belum banyak berkembang, sehingga literatur yang didapatkan masih sangat terbatas. Namun demikian usaha dengan meneliti ini akan sangat bermanfaat bila dikembangkan lebih lanjut tentang pemanfaatan aplikasi $e$ commerce sebagai strategi bisnis kewirausahaan yang berkembang di Indonesia khususnya Jawa Tengah, agar dapat digunakan dengan baik sehingga pengembangan $e$ commerce dapat dijadikan pilihan yang tepat, guna memberikan kepuasan layanan terhadap pelanggan dalam menggunakan website. Penelitian ini akan menghasilkan luaran berupa cara menganalisis faktor-faktor yang berpengaruh terhadap kemanfaatan website dengan model TAM analisisnya SEM software SPSS AMOS 22 .

Berdasarkan latar belakang masalah di atas, maka rumusan masalah dalam penelitian ini adalah sebagai berikut :

a. Bagaimana pengaruh Website terhadap Kemudahan akses internet dengan manfaat Ecommerce strategi bisnis kewirausahaan?

b. Bagaimana pengaruh Perusahaan terhadap Manfaat e-commerce dengan Sikap, Niat dan Kepuasan penerimaan Website/ Ecommerce sebagai bisnis kewirausahaan?

c. Bagaimana pengaruh Kemudahan akses internet dengan Sikap, Niat dalam memanfaatkan e-commerce sebagai strategi bisnis kewirausahaan terhadap kepuasan layanan dan penerimaan website/ Ecommerce Perusahaan?

Sesuai dengan rumusan masalah di atas, maka tujuan penelitian ini adalah sebagai berikut :

a. Mengetahui seberapa besar pengaruh Website terhadap Kemudahan akses internet dengan manfaat Ecommerce strategi bisnis kewirausahaan? 
b. Mengetahui seberapa besar Perusahaan terhadap Manfaat e-commerce dengan Sikap, Niat dan Kepuasan penerimaan Website/ Ecommerce sebagai bisnis kewirausahaan?

c. Mengetahui seberapa besar Kemudahan akses internet dengan Sikap, Niat dalam memanfaatkan e-commerce sebagai strategi bisnis kewirausahaan terhadap kepuasan layanan dan penerimaan website/Ecommerce Perusahaan?

Manfaat dari penelitian ini adalah sebagai berikut:

a. Bagi Dunia Bisnis Kewirausahaan

Diharapkan hasil penelitian ini dapat memberikan informasi mengenai analisa pemanfaatan E-commerce sebagai strategi bisnis kewirausahaan yang berkembang di Indonesia khususnya Jawa Tengah, sehingga pengembangan e-commerce dapat dijadikan pilihan yang tepat, guna memberikan kepuasan pelanggan dalam menggunakan Website.

\section{b. Bagi Peneliti}

Hasil penelitian ini dapat dijadikan bahan kajian untuk menentukan langkah pemanfaatan teknologi informasi melalui Ecommerce, sehingga dengan strategi bisnis yang relevan dapat digunakan sebagai dasar untuk mengembangkan bisnis kewirausahaan (on line).

c. Bagi Masyarakat

Hasil penelitian ini dapat dijadikan sebagai bahan referensi dan tambahan pengetahuan mengenai pengembangan teknologi informasi serta untuk penelitian penelitian selanjutnya untuk lebih diteliti secara mendalam faktor-faktor yang berpengaruh dan berhubungan antar variabel yang diteliti. Hal ini dapat menjadi rujukan bagi Pengusaha untuk menentukan faktorfaktor yang perlu ditingkatkan dalam perkembangan masa depan.

Pengertian e-commerce dapat dilihat dari tiga aspek yaitu perdagangan (commerce), fungsi bisnis dan kerjasama (collaboration). Berdasarkan ketiga aspek tersebut, $e$ commerce dapat didefinisikan sebagai aplikasi teknologi jejaring telekomunikasi (telecommunication network) untuk melakukan transaksi bisnis, pertukaran informasi dan menjaga hubungan dengan konsumen sebelum, selama dan setelah proses transaksi (Costa, 2001).

Menurut Suryana (2008) Fungsi dan peran wirausaha dapat dilihat melalui dua pendekatan yaitu secara mikro dan makro. Secara mikro, wirausaha memiliki dua peran, yaitu sebagai penemu (innovator) dan perencana (planner). Sebagai penemu, wirausaha menemukan dan menciptakan sesuatu yang baru, seperti produk, tekhnologi, cara, ide, organisasi, dan sebagainya. Sebagai perencana, wirausaha berperan merancang tindakan dan usaha baru, merencanakan strategi usaha yang baru, merencanakan ideide dan peluang dalam meraih sukses, menciptakan organisasi perusahaan yang baru, dan lain-lain. Secara makro, peran wirausaha adalah menciptakan kemakmuran, pemerataan kekayaan, dan kesempatan kerja yang berfungsi sebagai mesin pertumbuhan perekonomian suatu negara. Berkaitan dengan aspek lingkungan perusahaan, Wilkinson (2002) menyatakan bahwa perusahaan akan tumbuh bilamana lingkungan aturan/kebijakan mendukung, transaksi dikelola dengan baik, harga stabil dan dapat diprediksi, informasi dapat dipercaya dan website mudah diakses.

$$
\text { Adamson dan Shine (2003) }
$$

menyebutkan bahwa hasil riset-riset empiris menunjukkan bahwa persepsi kemanfaatan merupakan faktor yang cukup kuat mempengaruhi penerimaan, adopsi dan penggunaan sistem oleh pengguna. Penelitian-penelitian sebelumnya juga menunjukkan bahwa terdapat hubungan yang positif antara persepsi kebermanfaatan dengan penggunaan layanan online. Begitu juga dengan niat yang merupakan penentu utama dari perilaku nyata. Attitude Toward Using dalam TAM dikonsepkan sebagai sikap terhadap penggunaan sistem yang berbentuk penerimaan atau penolakan sebagai dampak bila seseorang menggunakan suatu teknologi dalam pekerjaannya. menganalisis hubungan dan pengaruhnya dengan menggunakan analisis SEM (Structural Equation Modeling) software AMOS. Dalam penelitian ini akan 
menyelidiki faktor eksternal atas penerimaan terhadap manfaat e-commerce dalam aspek kewirausahaan dan persepsi kemudahan akses website yang mempengaruhi sikap kearah penggunaan dan niat pengguna untuk menggunakan menuju kearah kepuasan layanan pelanggan dan penerimaan Website.

\section{METODE}

\section{Desain Penelitian}

Penelitian ini merupakan jenis penelitian kuantitatif dan menggunakan pendekatan yang bersifat lapangan. Jenis penelitian kuantitatif karena memandang bahwa realitas / fenomena dapat diklasifikasikan, relatif tetap, konkrit, terukur dan hubungan gejala bersifat sebab akibat. Penelitian ini dilakukan pada populasi dan sampel tertentu yang representatif. Penelitian ini bersifat deduktif karena untuk menjawab rumusan masalah yang digunakan konsep / teori sehingga dapat merumuskan hipotesis. Hipotesis tersebut selanjutnya di uji melalui pengumpulan data dilapangan. (Sugiyono, 2010 :14). Penelitian ini juga disebut sebagai penelitian kausalitas yang bertujuan untuk menganalisis hubungan dan pengaruh (sebabakibat) dari dua atau lebih fenomena. Sumber Data penelitian ini adalah Data Primer dan Data Sekunder

\section{a. Data Primer}

Data primer adalah data yang diperoleh peneliti dari sumber asli. Data dikumpulkan sendiri oleh peneliti langsung dari sumber pertama atau tempat obyek penelitian beserta team peneliti. Data primer dalam penelitian ini diperoleh dari penyebaran kuisioner terhadap pelanggan Femax CV. Karya Solenoida.

b. Data Sekunder

Data sekunder berasal dari internal dan eksternal antara lain data yang berasal dari laporan arsip maupun publikasi dari internet dan data komersial.

\section{Populasi dan Sampel}

Populasi dan sampel dalam penelitian ini adalah sebagai berikut :

a. Populasi adalah wilayah generalisasi yang terdiri atas obyek atau subyek yang memiliki kualitas dan karakteristik tertentu yang diterapkan oleh peneliti untuk dipelajari dan kemudian ditarik kesimpulannya. (Sugiyono, $2010: 117)$

b. Sampel adalah bagian dari jumlah atau karakteristik tertentu yang diambil dari suatu populasi yang akan diteliti secara rinci. Ukuran sampel dalam SEM dengan model estimasi menggunakan Maksimum Likelihood (ML) minimun yaitu diperlukan 100 sampel. ( Ghazali, $2011: 64$ )

\section{Instrumen Penelitian}

Variabel Penelitian adalah suatu atribut sifat atau nilai obyek dari obyek atau kegiatan yang mempunyai variasi tertentu yang ditetapkan oleh peneliti untuk dipelajari dan kemudian ditarik kesimpulannya. Jadi variabel adalah konsep yang mempunyai bermacam-macam nilai berupa kuantitatif maupun kualitatif yang nilainya berubah-ubah. (Sugiyono, $2010: 110$ )

Variabel Website (X1) memiliki indikator berupa Tampilan Website (X1.1), Daya Tarik website (X1.2), Informasi Fitur Website (X1.3) dan Data Informasi Website (X1.4).

Tabel 1: Indikator Website

\begin{tabular}{|l|l|}
\hline Nama Variabel & \multicolumn{1}{|c|}{ Indikator } \\
\hline Website $(\mathrm{X} 1)$ & X1.1. Tampilan website \\
\hline & X1.2. Daya Tarik Website \\
\cline { 2 - 2 } & X1.3. Informasi Fitur website \\
\cline { 2 - 2 } & X1.4. Data Informasi Website \\
\hline
\end{tabular}

Variabel Perusahaan (X2) memiliki indikator berupa Kreatifitas dan Inovasi Pebisnis (X2.5),
Wawasan Luas/Global (X2.6), dan Karyawan Giat dan Kreatif (X2.7). 
Tabel 2: Indikator Sumber Daya Perusahaan

\begin{tabular}{|l|l|}
\hline Nama Variabel & \multicolumn{1}{c|}{ Indikator } \\
\hline Perusahaan (X2) & X2.5. Kreatifitas dan Inovasi Pebisnis \\
\cline { 2 - 3 } & X2.6. Wawasan luas / global \\
\cline { 2 - 2 } & X2.7. Karyawan giat dan kreatif \\
\hline
\end{tabular}

Variabel Manfaat E-Commerce (Y1) dengan indikator berupa E-Commerce menjadi Citra Perusahaan (Y1.8), Kepercayaan dan Pelayanan Publik (Y1.9), E-Commerce

Tabel 3: Indikator Persepsi Manfaat E-Commerce

\begin{tabular}{|c|l|}
\hline Nama Variabel & \multicolumn{1}{|c|}{ Indikator } \\
\hline Manfaat E-Commerce (Y1) & Y1.8. E-Commerce menjadi Citra Perusahaan \\
\cline { 2 - 3 } & Y1.9. Kepercayaan dan pelayanan publik \\
\cline { 2 - 2 } & Y1.10. E-Commerce memberi informasi baru \\
\cline { 2 - 2 } & Y1.11. Adanya E-Commerce dapat pelanggan baru \\
\hline
\end{tabular}

Variabel Kemudahan Akses Internet (Y2) memiliki indikator yaitu bisa untuk transaksi ecommerce (Y2.12), Operasi internet yang memberi Informasi Baru (Y1.10) dan Adanya E-Commerce mendapat Pelanggan Baru (Y1.11).

Tabel 4: Indikator Kemudahan Akses Internet

\begin{tabular}{|l|l|}
\hline \multicolumn{1}{|c|}{ Nama Variabel } & \multicolumn{1}{c|}{ Indikator } \\
\hline Kemudahan Akses Internet (Y2) & Y2.12. Bisa untuk transaksi e-commerce \\
\cline { 2 - 3 } & Y2.13. Operasi internet yang mudah \\
\cline { 2 - 2 } & Y2.14. Fleksibel Penggunaannya \\
\hline
\end{tabular}

Variabel Sikap Pengguna Internet (Y3) memiliki indikator sebagai berikut : Internet yang menyenangkan (Y3.15), Internet pilihan mudah (Y2.13), dan fleksibel penggunaannya (Y2.14).

Tabel 5: Indikator Sikap Pengguna Internet

\begin{tabular}{|l|l|}
\hline \multicolumn{1}{|c|}{ Nama Variabel } & \multicolumn{1}{c|}{ Indikator } \\
\hline Sikap Pengguna Internet (Y3) & Y3.15. Internet yang menyenangkan \\
\cline { 2 - 2 } & Y3.16. Internet pilihan yang bijaksana \\
\cline { 2 - 2 } & Y3.17. Internet untuk mencari Informasi \\
\cline { 2 - 2 } & Y3.18. Internet sesuatu yang menguntungkan \\
\hline
\end{tabular}

Variabel Niat Pengguna E-Commerce (Y4) memiliki indikator sebagai berikut : Minat menggunakan E-Commerce ( Y4.19), Transaksi

Tabel 6 : Indikator Niat Pengguna E-Commerce yang bijaksana (Y3.16), Internet untuk mencari informasi (Y3.17), dan Internet sesuatu yang menguntungkan (Y3.18). efektif melalui E-Commerce (Y4.20) dan ECommerce menjadi pilihan hidup (Y4.21). 


\begin{tabular}{|c|l|}
\hline Nama Variabel & \multicolumn{1}{c|}{ Indikator } \\
\hline Niat Pengguna E-Commerce (Y4) & Y4.19. Minat menggunakan E-Commerce \\
\cline { 2 - 2 } & Y4.20. Transaksi efektif melalui E-Commerce \\
\cline { 2 - 2 } & Y4.21. E-Commerce pilihan hidup \\
\hline
\end{tabular}

Variabel Kepuasan Layanan dan Penerimaan Website (Y5) memiliki indikator sebagai berikut : Puas menggunakan E-Commerce (Y5.22), Puas keberadaan Website
Perusahaan (Y5.23), Informasi dalam Website bisa mempengaruhi Pelanggan (Y5.24) dan Menerima keberadaan Website (Y5.25)

Tabel 7 : Indikator Kepuasan \& Penerimaan Website

\begin{tabular}{|c|l|}
\hline \multicolumn{1}{|c|}{ Nama Variabel } & \multicolumn{1}{c|}{ Indikator } \\
\hline Kepuasan \& Penerimaan Web (Y5) & Y5.22. Puas menggunakan E-Commerce \\
\cline { 2 - 3 } & Y5.23. Puas keberadaan website perusahaan \\
\cline { 2 - 2 } & Y5.24. Informasi Website mempengaruhi \\
\cline { 2 - 2 } & Y5.25. Menerima keberadaan Website \\
\hline
\end{tabular}

\section{Teknik Pengumpulan Data}

Teknik Pengumpulan Data penelitian ini adalah sebagai berikut :

\section{a. Metode Angket (Kuisioner)}

Angket atau kuisioner adalah teknik pengumpulan data yang dilakukan dengan cara memberikan seperangkat daftar pertanyaan atau pernyataan tertulis untuk memperoleh keterangan dari sejumlah responden. (Sugiyono, 2010). Instrumen yang diberikan kepada responden menggunakan teknik skala likert 5 poin untuk mengukur variabel penelitian. Responden nantinya memilih jawaban dari pernyataan positif dengan 5 alternatif jawaban yang ada, yaitu sebagai berikut : a. Sangat Setuju (SS) dengan skor 5, b. Setuju (S) dengan skor 4, c. Ragu-Ragu (RR) dengan skor 3, d. Tidak Setuju (TS) dengan skor 2, e. Sangat Tidak Setuju (STS) dengan skor 1

\section{b. Metode Wawancara}

Wawancara adalah metode untuk mengumpulkan data dengan tanya jawab secara lisan dan bertatap muka langsung atara seorang atau beberapa orang yang diwawancarai. Metode untuk mendapatkan data penelitian melalui pertanyaan kuisioner yang diberikan kepada pelanggan Femax. Data primer didapat dari data pelanggan yang mengisi kuisioner, dan data sekunder adalah jawaban yang ada dalam pertanyaan. Kuisioner yang di gunakan sebagai instrument untuk mendapatkan data Penelitian.

\section{Teknik Analisa Data}

SEM dapat dideskripsikan sebagai suatu analisis yang mengganungkan pendekatan analisis factor (factor analysis), model struktural ( structural model) dan analisis jalur (path analysis). Menurut Imam Ghazali (2011), SEM merupakan gabungan dari metode statistik yang terpisah yaitu analisis faktor (factor analysis) serta model persamaan ( simultaneous equation modeling). Sedangkan menurut Santoso (2012) ada beberapa tahapan pokok yang akan dilalui untuk menggunakan SEM dalam sebuah kegiatan penelitian, yaitu :

a. Membuat sebuah model SEM (Model Specification).

Pada tahap ini, sebuah model "dengan berdasar teori tertentu" dibuat, baik dalam bentuk equation (persamaan-persamaan matematis) maupun dalam bentuk diagram 
(gambar). Diagram akan memasukkan measurement model dan structural model.

b. Menyiapkan desain penelitian dan pengumpulan data.

Setelah model dibuat, sebelum model diuji, akan dilakukan pengujian asumsi-asumsi yang seharusnya dipenuhi dalam SEM, perlakuan terhadap missing data (jika ada dan cukup banyak), mengumpulkan data, dan sebagainya.

c. Model Identification

Setelah model dibuat dan desain sudah ditentukan, pada model dilakukan uji identifikasi, apakah model dapat dianalisis lebih lanjut yaitu perhitungan besarnya degree of freedom.

d. Menguji Model (Model Testing dan Model Estimation)

Setelah model dibuat dan dapat diidentifikasi, tahapan dilanjutkan dengan menguji measurement model dan kemudian menguji structural model. Dari pengujian measurement model, akan didapat keeratan hubungan antara indikator dengan konstruknya. Jika measurement model dapat dianggap valid, pengujian dilanjutkan pada structural model untuk memperoleh jumlah korelasi yang menunjukkan hubungan antar konstruk.

\section{HASIL}

Hasil perhitungan menggunakan AMOS 22 hasil output pada uji normalitas (Assessment of normality) data diperoleh hasil multivariate sebesar -1,115 artinya sebuah distribusi dikatakan normal jika angka cr skewness atau angka cr kurtosis ada diantara $-2,58$ sampai $+2,58$.

\section{Uji Normalitas Data}

Tabel 8: Normalitas Data

\begin{tabular}{|c|c|c|c|c|c|c|}
\hline Variable & $\min$ & $\max$ & skew & c.r. & kurtosis & c.r. \\
\hline Y5.25 & 3,000 & 5,000 &,- 134 &,- 549 & $-1,482$ & $-3,025$ \\
\hline Y5.24 & 3,000 & 5,000 &,- 376 & $-1,535$ & $-1,358$ & $-2,772$ \\
\hline Y5.23 & 3,000 & 5,000 &, 221 &, 902 & $-1,401$ & $-2,859$ \\
\hline Y5.22 & 3,000 & 5,000 &,- 214 &,- 873 & $-1,457$ & $-2,974$ \\
\hline Y4.21 & 3,000 & 5,000 &,- 152 &,- 619 & $-1,162$ & $-2,373$ \\
\hline Y4.20 & 3,000 & 5,000 &,- 228 &,- 931 & $-1,148$ & $-2,342$ \\
\hline Y4.19 & 3,000 & 5,000 &, 221 &, 902 & $-1,401$ & $-2,859$ \\
\hline Y3.18 & 3,000 & 5,000 &,- 306 & $-1,247$ & $-1,116$ & $-2,278$ \\
\hline Y3.17 & 3,000 & 5,000 &,- 174 &,- 710 & $-1,471$ & $-3,003$ \\
\hline Y3.16 & 3,000 & 5,000 &, 141 &, 577 & $-1,447$ & $-2,954$ \\
\hline Y3.15 & 3,000 & 5,000 &,- 114 &,- 464 & $-1,164$ & $-2,375$ \\
\hline Y2.14 & 3,000 & 5,000 &,- 256 & $-1,044$ &,- 943 & $-1,926$ \\
\hline Y2.13 & 3,000 & 5,000 & 1,348 & 5,504 & 1,332 & 2,720 \\
\hline Y2.12 & 3,000 & 5,000 & 1,137 & 4,641 & 2,068 & 4,220 \\
\hline Y1.11 & 3,000 & 5,000 &, 693 & 2,831 &, 753 & 1,537 \\
\hline Y1.10 & 3,000 & 5,000 &, 221 &, 902 & $-1,401$ & $-2,859$ \\
\hline Y1.9 & 4,000 & 5,000 &, 723 & 2,952 & $-1,477$ & $-3,015$ \\
\hline Y1.8 & 4,000 & 5,000 &, 494 & 2,019 & $-1,756$ & $-3,583$ \\
\hline X2.7 & 3,000 & 5,000 &,- 016 &,- 066 & $-1,490$ & $-3,042$ \\
\hline
\end{tabular}




\begin{tabular}{|c|c|c|c|c|c|c|} 
X2.6 & 3,000 & 5,000 & $-1,264$ & $-5,162$ &, 297 &, 605 \\
\hline X2.5 & 3,000 & 5,000 &,- 095 &,- 388 & $-1,488$ & $-3,038$ \\
\hline X1.4 & 4,000 & 5,000 &,- 676 & $-2,758$ & $-1,544$ & $-3,151$ \\
\hline X1.3 & 3,000 & 5,000 & 1,088 & 4,441 & 1,727 & 3,525 \\
\hline X1.2 & 3,000 & 5,000 &, 736 & 3,005 &,- 681 & $-1,390$ \\
\hline X1.1 & 3,000 & 5,000 &,- 464 & $-1,896$ & $-1,002$ & $-2,045$ \\
\hline Multivariate & & & & & $-8,197$ & $-1,115$ \\
\hline
\end{tabular}

\section{Uji Measurement Model}

Model yang baik harus memenuhi uji goodness of fit agar hasil estimasi memenuhi ketentuan melalui uji validitas measurement model

Tabel 9 : Goodness of Fit

\begin{tabular}{|c|c|c|c|c|c|}
\hline $\begin{array}{c}\text { Goodness-of- } \\
\text { fit }\end{array}$ & $\begin{array}{c}\text { Cut-of- } \\
\text { value }\end{array}$ & $\begin{array}{c}\text { Model } \\
\text { Awal }\end{array}$ & $\begin{array}{c}\text { Modifikasi } \\
\text { model pertama }\end{array}$ & $\begin{array}{c}\text { Modifikasi } \\
\text { model Akhir }\end{array}$ & Keterangan \\
\hline Chi-square $\left(\mathrm{X}^{2}\right)$ & $\leq 305,041$ & 380,782 & 313,581 & 288,474 & Baik \\
\hline Probabilitas $(p)$ & $\geq 0,05$ & 0,000 & 0,013 & 0,073 & Baik \\
\hline RMSEA & $\leq 0,080$ & 0,066 & 0,046 & 0,036 & Baik \\
\hline GFI & $\geq 0,900$ & 0,787 & 0,818 & 0,829 & Marginal \\
\hline AGFI & $\geq 0,900$ & 0,740 & 0,772 & 0,782 & Marginal \\
\hline CMIN/DF & $\leq 2,00$ & 1,432 & 1,206 & 1,131 & Baik \\
\hline CFI & $\geq 0,900$ & 0,500 & 0,767 & 0,854 & Marginal \\
\hline TLI & $\geq 0,900$ & 0,437 & 0,731 & 0,829 & Marginal \\
\hline
\end{tabular}

3. Menguji Model dengan Modification Indices model path diagram

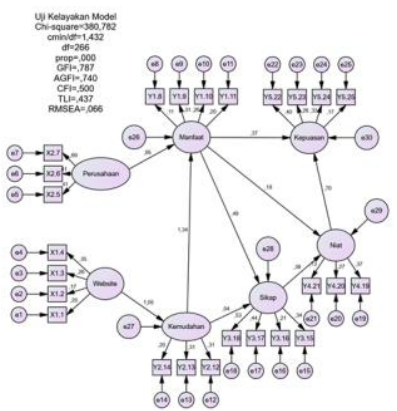

Gambar model awal

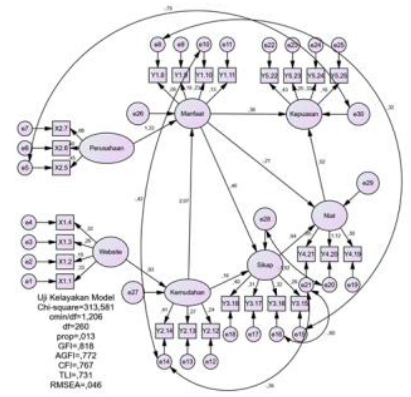

Gambar modifikasi pertama

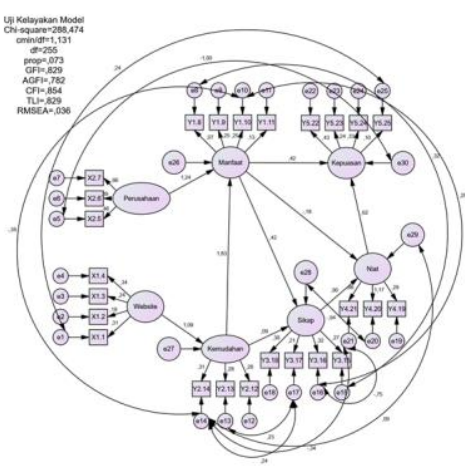

Gambar modifikasi akhir 
Pengaruh adanya Website Perusahaan dengan kemudahan akses internet dapat diketahui dari hasil perhitungan standardized regression weights dijelaskan bahwa Manfaat adanya aplikasi e-commerce sangat dibutuhkan oleh Pelanggan / Konsumen dengan Kemudahan mengakses di Internet. Website memiliki pengaruh langsung terhadap variabel mudah sebesar 1,087, variabel Perusahaan berpengaruh terhadap variabel Manfaat sebesar 1,236 dan yang tertinggi pengaruhnya adalah variabel Kemudahan terhadap variabel Manfaat sebesar 1,630. Selanjutnya pengaruh variabel Sikap mempengaruhi variabel Niat sebesar 0,898 , variabel Niat mempengaruhi variabel Kepuasan sebesar 0,615 . Hal ini menunjukkan bahwa Kepuasan Pelanggan ditentukan oleh sikap konsumen untuk memesan layanan dari Perusahaan dengan niat mau menggunakan aplikasi yang ada. Sedangkan variabel Manfaat berpengaruh terhadap variabel Kepuasan sebesar 0,423 dan variabel Manfaat berpengaruh terhadap variabel Sikap sebesar 0,419 . Namun demikian variabel yang terkecil adalah variabel Kemudahan berpengaruh terhadap variabel Sikap sebesar 0,088 dan yang tidak berpengaruh hanya variabel Manfaat terhadap variabel Niat sebesar 0,175 . Dengan demikian dapat dijelaskan bahwa hasil pengujian penelitian analisis pemanfaatan aplikasi e-commerce dalam aspek kewirausahaan terhadap kepuasan konsumen adalah sebagai berikut:

a. Website berpengaruh terhadap Kemudahan nilainya 1,087, dapat diartikan bahwa secara langsung adanya Website mempengaruhi kemudahan akses internet bagi konsumen atas kepuasan penggunaan kemudahan aplikasi $e$-commerce.

b. Perusahaan berpengaruh terhadap Manfaat nilainya 1,236, dapat diartikan bahwa Perusahaan yang memiliki Sumber Daya yang baik akan mempengaruhi terhadap manfaat konsumen memperoleh kualitas layanan dari adanya aplikasi $e$ commerce dalam Website. c. Kemudahan akses internet berpengaruh paling besar terhadap Manfaat penggunaan adanya aplikasi e-commerce nilainya 1,630 yang dapat diartikan bahwa kemudahan mempengaruhi hubungan secara langsung terhadap manfaatnya. Karena bisa saja kemudahan akses internet mampu menghubungkan informasi di internet menggunakan aplikasi sehingga harapan konsumen membutuhkan layanannya menjadi mempengaruhi kepuasan konsumen.

d. Kemudahan akses internet berpengaruh terhadap Sikap nilainya 0,088, dapat diartikan bahwa kemudahan memiliki pengaruh terhadap sikap konsumen menggunakan aplikasi secara langsung, sehingga perlu adanya penerapan aplikasi bagi Perusahaan untuk keberlangsungan usaha dimasa depan.

e. Manfaat berpengaruh terhadap Sikap nilainya 0,419 , dapat diartikan bahwa manfaat memiliki pengaruh juga terhadap sikap menggunakan konsumen atas aplikasi yang dibuat oleh Perusahaan walaupun hasilnya kecil namun tetap berpengaruh secara langsung.

f. Sikap berpengaruh terhadap Niat nilainya 0,898 , dapat diartikan bahwa Sikap pengguna dalam memanfaatkan aplikasi memiliki pengaruh yang baik terhadap niat, karena mungkin adanya niat mencari informasi yang dibutuhkan sehingga mencarinya lewat media sosial atau internet yang dapat mempengaruhinya.

g. Manfaat tidak berpengaruh terhadap Niat nilainya $-0,175$, dapat diartikan bahwa Manfaat layanan yang diberikan Perusahaan tidak mempengaruhi niat konsumen menggunakan layanan aplikasinya.

h. Niat berpengaruh terhadap Kepuasan nilainya 0,615 , dapat diartikan bahwa Niat menggunakan aplikasi berpengaruh dengan kepuasan penerimaan website walaupun 
hasilnya kecil. Namun demikian faktor niat memanfaatkan aplikasi menggunakan ini mempengaruhi penerimaan website dan kepuasan menggunakan layanan e-commerce yang disediakan oleh Perusahaan.

i. Manfaat berpengaruh terhadap Kepuasan nilainya 0,423 , dapat diartikan bahwa manfaat adanya aplikasi website e-commerce memiliki pengaruh terhadap kepuasan konsumen. Oleh karena itu Perusahaan perlu membuat layanan yang bermanfaat bagi konsumen sehingga mempengaruhi konsumen menerima keberadaan website atau penggunaan aplikasi e-commerce oleh Perusahaan.

\section{KESIMPULAN}

Kesimpulan dari analisis pemanfaatan e-commerce dilihat dari pengaruh desain/fitur website dengan kemudahan akses internet dapat diketahui dari hasil perhitungan tertinggi pengaruhnya adalah variabel Kemudahan akses Internet terhadap variabel Manfaat Ecommerce sebesar 1,630. Sedangkan yang tidak berpengaruh adalah variabel Manfaat terhadap variabel Niat sebesar $-0,175$. Dengan demikian maka perlu adanya tindak lanjut bagi Perusahaan untuk selalu mengembangkan Aplikasi E-Commerce di masa yang akan datang agar kepuasan Pelanggan dalam memanfaatkan internet melalui informasi website dapat meningkat.
1. Adamson, I., \& Shine, J. (2003). Extending the New Technology Acceptance Model to Measure the End User Information Systems Satisfaction in a Mandatory Environment: A Bank's Treasury. Technology Analysis \& Strategic Management. Vol.15 No.4 : pp 441-445.

2. Costa, E.d. 2001, Global e-commerce strategies for small businesses, MIT Press, Cambridge, Mass.

3. Ghozali, Imam. 2011. Model Persamaan Struktural: Konsep \& Aplikasi Dengan Program Amos 19.0. Cetakan Keempat. Semarang: Penerbit Badan Penerbit Universitas Diponegoro.

4. Santoso, S. (2007). Structural Equation Modeling: Konsep dan aplikasi dengan AMOS Membuat dan Menganalisis Model SEM Menggunakan Program AMOS. Jakarta: PT. Elex Media Komputindo

5. Santoso, S (2012). Analisis SEM Menggunakan AMOS. Jakarta : PT. Elex Media Komputindo.

6. Sugiyono. 2010. Metode Penelitian Pendidikan Pendekatan Kuantitatif, kualitatif, dan R\&D. Bandung: Alfabeta

7. Suryana, Kewirausahaan Pedoman Praktis: Kiat dan Proses Menuju Sukses, Jakarta, Salemba Empat, 2008,h. 4

8. Vaidyanathan, G. (2005) User Acceptance Of Digital Library: An Empirical Exploration of Individual And System Components. Issues in Information System, Volume VI, No.2. www.emeraldinsight.com /Insight/ViewContentServlet?Filename=/publ ished/emerald fulltext article/pdf/ 0260240403_ref.html.

9. Wilkinson, B., 2002, Small, Micro and Medium Enterprise Development: Expanding the Option for Debt and Equity Finance. Financial Sector Workshop, National Economic Development and Labour Council (NEDLAC) Johanesburg, South Africa, Iris, April 6.

\section{DAFTAR PUSTAKA}

